\title{
Graphene Based Electrochemical DNA Biosensor for Detection of False Smut of Rice (Ustilaginoidea virens)
}

\author{
Kritika Rana, Jagjiwan Mittal, Jagriti Narang", Annu Mishra, and Ramesh Namdeo Pudake (iD)* \\ Amity Institute of Nanotechnology, Amity University Uttar Pradesh, Noida 201303, UP, India \\ ${ }^{\top}$ Current address: Department of Biotechnology, Jamia Hamdard, New Delhi 110062, UP, India
}

(Received on November 18, 2020; Revised on April 19, 2021; Accepted on May 15, 2021)

False smut caused by Ustilaginoidea virens is an important rice fungal disease that significantly decreases its production. In the recent past, conventional methods have been developed for its detection that is time-consuming and need high-cost equipments. The research and development in nanotechnology have made it possible to assemble efficient recognition interfaces in biosensors. In this study, we present a simple, sensitive, and selective oxidized graphene-based geno-biosensor for the detection of rice false smut. The biosensor has been developed using a probe DNA as a biological recognition element on paper electrodes, and oxidized graphene to enhance the limit of detection and sensitivity of the sensor. Probe single-stranded DNA (ssDNA) and target ssDNA hybridization on the interface surface has been quantitatively measured with the electrochemical analysis tools namely, cyclic voltammetry, and linear sweep voltammetry. To confirm the selectivity of the device, probe hybridization with non-complementary ssDNA target has been studied. In our study, the developed sensor was able to detect up to $10 \mathrm{fM}$ of target ssDNA. The paper electrodes were employed to produce an effective and cost-effective platform for the im-

*Corresponding author.

Phone) +91-7503149960, +91-1204392130, FAX) +91-1202432200

E-mail: rnpudake@amity.edu

ORCID

Ramesh Namdeo Pudake

https://orcid.org/0000-0003-0124-8537

Handling Editor : Junhyun Jeon

(c) This is an Open Access article distributed under the terms of the Creative Commons Attribution Non-Commercial License (http:// creativecommons.org/licenses/by-nc/4.0) which permits unrestricted noncommercial use, distribution, and reproduction in any medium, provided the original work is properly cited.

Articles can be freely viewed online at www.ppjonline.org. mobilization of the DNA and can be extended to design low-cost biosensors for the detection of the other plant pathogens.

Keywords : DNA probe, false smut, graphene, nanosensors, plant pathogen electrochemical

Rice is the third important crop grown worldwide after maize and sugarcane, which is important for the economy and food security of the whole world. India is the secondlargest producer of rice in the world after China (Khatkar et al., 2016). However, the risk posed by crop damage due to pests, diseases, natural disasters, etc. hinders the food security of the country. It is infected by several different pathogens, and rice false smut is currently one of the most devastating fungal diseases which cause a widespread decrease in yield. The disease is caused by Ustilaginoidea virens, which poses a serious problem in the rice-growing countries around the world (Bhargava et al., 2018; Sun et al., 2020; Tanaka and Tanaka, 2008). Rice false smut reduces the quality and yield of rice, subsequently leading to crop loss (Lu et al., 2009). Moreover, it threatens food safety due to the production of ustiloxins (mycotoxins produced by $U$. virens) that are toxic to animals and humans (Jiehua et al., 2019; Wang et al., 2016). In India, the pathogen causes $5-85 \%$ yield losses in various states (Bhargava et al., 2018). The $44 \%$ losses have been reported in Punjab and Uttar Pradesh (Pannu et al., 2010; Singh and Dube, 1978). For the proper and timely implementation of disease management strategies, knowledge of epidemiology is crucial to counteract the adverse effects of crop diseases (Zhou et al., 2003). The replacement of infected rice grains with false smut spore balls is a normal symptom of this disease. The false smut balls are first yellowish orange to green in colour, and finally, turn a greenish black. The life cycle of 
this biotrophic fungus involves both sexual and asexual stages, and sclerotia and chlamydospores has the potential to be primary inoculum source in the field condition (Jiehua et al., 2019). Based on field and laboratory observations, it has been reviewed that fungus have a tendency to first infect the rice spikelets at the booting stage and ultimately resulting in rice false smut disease. However, it not clear when and how the conidia enter the spikelets in field conditions (Jiehua et al., 2019).

The current research focus is mainly on identifying the resistance genes and understanding more about the molecular mechanism of resistance for rice false smut. However, in addition to this, there is further need for research on knowing how this disease epidemic can be accurately predicted by rapid and early detection methods for effective control. One of the existing techniques for the detection of plant pathogens is isolating and examining the pathogen on nutrient media. But this method is time-consuming ( $\mathrm{Li}$ et al., 2013; Zhou et al., 2003). Other detection techniques like enzyme-linked immunosorbent assay, direct tissue blot immunoassay, PCR, reverse transcription polymerase chain reaction, etc. have also been used for early detection of infestation. Recently, a method for the detection of Ustiloxin $B$ protein by indirect competitive enzyme-linked immunosorbent assay with specific monoclonal antibody has been reported (Fu et al., 2015). PCR based method using specific primers have also been successfully used to detect the fungus infection in rice plant (Chen et al., 2014; Tang et al., 2017). In another study, a 212 bp segment of $U v G-\beta 1$ gene was used to design the primers for loopmediated isothermal amplification assay. In this study, the researchers were able to detect a minimum of $1 \mathrm{pg}$ of target genomic DNA for the specific detection of $U$. virens (Yang et al., 2018). Even though these techniques produce accurate results, they require complex instrumentation, are time-intensive, and it is hard to use them in-field condition for real-time monitoring of the disease. Therefore, we need to develop new and advanced biosensor systems for early, fast, and efficient disease detection in crop plants (Khater et al., 2017).

Biosensors for plant pathogen detection are broadly classified based on transduction elements, biorecognition elements, electrochemical techniques, and biosensor performance. Bioreceptors like enzymes, DNA, antibodies, cells, etc. which are capable of recognizing analyte or compound of interest are used in recent biosensors (Cesewski and Johnson, 2020). The biological signals can be transduced into a physical, chemical, thermal, optical, or electrochemical signal (Chen et al., 2020; Khan et al., 2020; Suvarnaphaet and Pechprasarn, 2017). The emergence of different nanomaterials has been a major development in the field of advanced sensors and biosensors. Nanomaterials provide a platform for the assembly of bio-recognition molecules and have a high surface area, electronic conductivity, and plasmonic properties. These attributes enhance the limit of detection. Different nanomaterials ranging from metal and metal oxide nanoparticles to quantum dots, carbon nanotubes, graphene, have been employed for biosensor applications in the field of plant pathogen detection (Fang and Ramasamy, 2015; Jain et al., 2021; Kumar and Arora, 2020; Li et al., 2020; Pudake et al., 2019).

Due to its two-dimensional structure, graphene is an excellent material for biosensor, as it is conductive, transparent, and biocompatible with low environmental impact and has a large surface area (Justino et al., 2017; MoralesNarváez and Merkoçi, 2019; Pumera, 2011). In biosensors, it offers enhanced limit of detection and the sensitivity which is highly desirable. It possesses excellent interfacial properties with ability to interact with various biomolecules, which helps in its functionalization that plays a major role in the sensing mechanism (Krishnan et al., 2019; Suvarnaphaet and Pechprasarn, 2017).

In this paper, we have developed a DNA-based electrochemical biosensor for simple and rapid detection of $U$. virens using oxidized graphene. The device consisted of a disposable two-electrode system fabricated on paper with conducting carbon ink and overcomes the additional need for glass or metal as in the three-electrode system. Moreover, paper-based lab-on-chip devices offer many advantages like minimized sample requirement, rapid analysis, small size (Cinti et al., 2017; Mathur et al., 2018). Our fabricated biosensor has exhibited high sensitivity, the enhanced limit of detection, and high selectivity.

\section{Materials and Methods}

Chemicals. Commercially available graphene produced by chemical vapor deposition method and that has few layers was procured and used in the present study. The other chemicals, like Sodium dihydrogen orthophosphate (monobasic) (purity 98\%), di-Sodium Hydrogen orthophosphate (dibasic) (99.5\%), and methylene blue (MB) were purchased from Fisher Scientific, India. The specific primers for gene G544 (GenBank accession no. KY617817) of various strains of $U$. virens were used to design the probe (Tang et al., 2017). The oligonucleotide sequences used in this study were as follows (Table 1), and were purchased from Integrated DNA Technologies, Inc. (IDT, Coralville, IW, USA). 
Table 1. The oligonucleotides used in this study

\begin{tabular}{ll}
\hline Name & Sequence \\
\hline Probe (P) & 5'-TCTTGGCTCCTCGGAAGCTC-3' \\
Target DNA1 (T1) & 5'-GAGCTTCCGAGGAGCCAAGA-3' \\
Target DNA2 (T2) & 5'-ACGCCGAGGACATGGAGCTTCCGAGGAGCCAAGAGACGGGTCCA-3' \\
Non-complementary DNA (N) & 5'-CATGTCTTGCCCAAAGATGCG-3' \\
\hline
\end{tabular}

Equipment's used. Nanostructure of the samples was studied by Jeol 2100 high resolution transmission electron microscope (HRTEM) with $200 \mathrm{KeV}$ beam energy and $<0.19 \mathrm{~nm}$ point resolution. Field emission scanning electron microscope (FESEM; JSM-7001F, Jeol, Tokyo, Japan) using $10 \mathrm{KeV}$ beam energy was used for visualization of the surface morphology of graphene. Elemental analysis was carried out by energy dispersive X-ray spectroscopy (EDS) in FESEM using silicon drift detectors. The crystal structure of the graphene was determined by X-ray diffraction (XRD; Bruker D2 phaser X-ray diffractometer, Bruker, Karlsruhe, Germany) using $\mathrm{CuK} \alpha, \lambda=1.5417$ radiations.

The electrochemical analysis and optimization of the

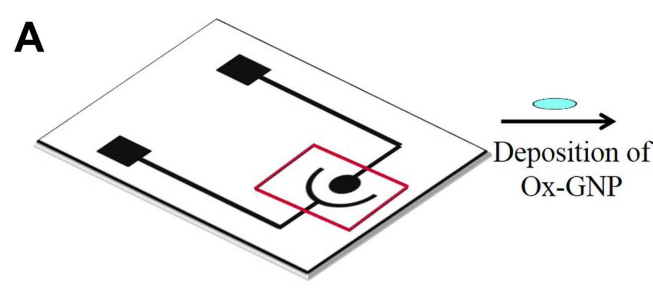

Paper electrode

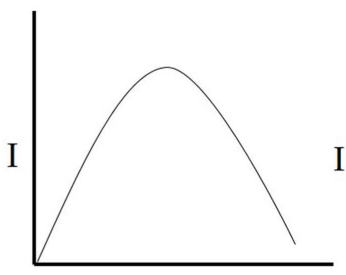

V

Stage II

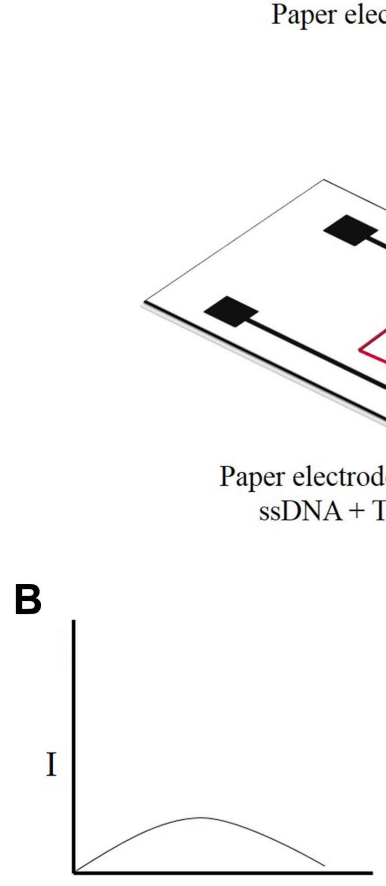

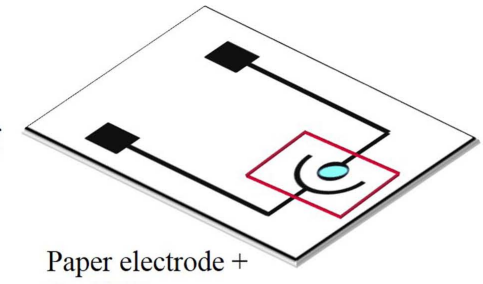
Ox-GNP

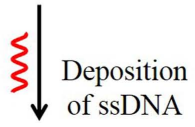

Paper electrode + Ox$\mathrm{GNP}+\mathrm{ssDNA}$
V

Stage I

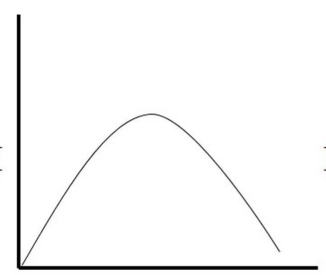

V

Stage III

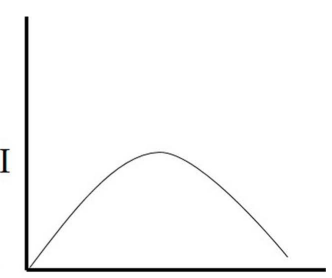

$\mathrm{V}$

Stage IV

Fig. 1. (A) Schematic of paper sensor fabrication. (B) The current response for bare electrode and Ox-GNP modified ePAD. The current response of Ox-GNP modified ePAD (stage II) increased substantially than the bare electrode (stage I). The current response for the ssDNA/Ox-GNP ePAD (stage III) decreased as compared to the Ox-GNP ePAD which is due to the non-conductive nature ssDNA. When the probe ssDNA hybridized with the complementary target ssDNA, MB gets intercalated between G-C base pairs of the hybrid DNA and a decrease in current response confirmed the hybridization of probe and target DNA (stage IV). Ox-GNP, oxidised graphene nanoparticles; ePAD, electrochemical paper-based analytical device; ssDNA, single-stranded DNA; MB, methylene blue. 
fabricated paper electrodes and sensing of hybridized target DNA and the selectivity of the sensor were performed using cyclic voltammetry (CV) and linear sweep voltammetry (LSV) on Autolab-PGSTAT-10 (Eco Chemie, Utrecht, Netherlands) electrochemical analysis system and Nova software package.

Fabrication of electrochemical paper-based analytical device (ePAD) integrated with oxidised graphene nanoparticles (Ox-GNP). The paper electrodes were printed with conducting carbon ink on cellulose paper using a stencil of choice, and ink was allowed to air dry. The electrode consisted of a working electrode (WE) and a counter electrode, its design was similar to an earlier report (Mathur et al., 2018), and schematic is given in Fig. 1. After the stenciling, the electrodes were measured for their resistance using a multimeter, and those with similar resistance were used for further experiments. Further, a square well was drawn using a wax crayon, around the working area of the electrode, to create a hydrophobic barrier to restrict the flow of electrolytes. After this, oxidized graphene $(10 \mu \mathrm{l})$ was drop-casted on the WE and kept at $65^{\circ} \mathrm{C}$ for 10 min. All the experiments were performed using the ePAD integrated with oxidized graphene (Mathur et al., 2018; Narang et al., 2017).

Fabrication of Ox-GNPs/ssDNA/ePAD. To prepare the probe DNA (P) solution, Tris-EDTA (TE) buffer was added to the lyophilized powder to make $100 \mu \mathrm{M}$ solution. Then, different concentrations of ssDNA were prepared from this stock by further diluting with TE buffer to get final concentrations of $20,40,60,80$, and $100 \mu \mathrm{M}$. These ssDNA concentrations were used for optimization using electrochemical studies i.e., CV and LSV. Five $\mu 1$ of probe DNA was drop-casted on Ox-GNPs modified ePAD for all five concentrations and dried at room temperature. For CV and LSV analysis, sodium phosphate buffer with $0.1 \mathrm{mM}$ $\mathrm{MB}$ was chosen as the electrolyte. The working conditions for sensors like temperature, $\mathrm{pH}$ and scan rate were also optimized. The modified ePAD with ssDNA concentration of $40 \mu \mathrm{M}$ was optimised for scan rate and response time, and the fabricated electrodes were tested with various concentrations of target DNA. For this target ssDNA (T1) in different concentration of $10 \mu \mathrm{M}, 100 \mathrm{nM}, 10 \mathrm{nM}, 100 \mathrm{pM}$, $10 \mathrm{pM}, 100 \mathrm{fM}$, and $10 \mathrm{fM}$ were prepared by serial dilution of $100 \mu \mathrm{M}$ concentration target DNA using TE buffer. The target ssDNA (T1) was immobilized on an electrode that already has probe ssDNA $(40 \mu \mathrm{M})$ on the Ox-GNPs modified ePAD, and just before the electrolyte was added to the electrode. Without drying, electrochemical tests were carried out right after immobilizing target DNA, using the sodium phosphate buffer. A similar procedure was repeated for the longer target ssDNA (T2). Further, to test the selectivity of the device, non-complementary ssDNA (N) was used, and the same procedure was followed.

\section{Results and Discussion}

Characterization of Ox-GNP. Structural and morphological characterization of Ox-GNPs was performed by FESEM, HRTEM, and XRD. FESEM micrograph in Fig. 2A shows pristine graphene sheets. These sheets are mostly flat and exist in various sizes and shapes. Some are larger in size than others and, most of them are irregular in shape. As shown in the higher magnification micrograph in Fig. 2B, cracks can be seen in the middle of the flat part, in some graphene. Folding is visible at the edges of sheets. Elemental analysis using EDS is tabulated in Fig. $2 \mathrm{C}$ that shows the presence of carbon and oxygen elements in the graphene. Study shows that the at $\%$ concentration of carbon and oxygen in graphene are $97.78 \%$ and $2.21 \%$, respectively.

HRTEM study using low magnification in Fig. 3A shows a flat few layer's graphene on the grid. Micrograph displays folding of the graphene layers at the edges by the dark black lines. A high magnification study of pristine graphene in Fig. 3B reveals the presence of few layers (1012) of graphene. These layers are clearly visible at various places in the micrograph. As shown in Fig. 3C, average inter-planner distance between the graphene layers is found to be $3.36 \AA$ which is similar to graphite (002) interplanar

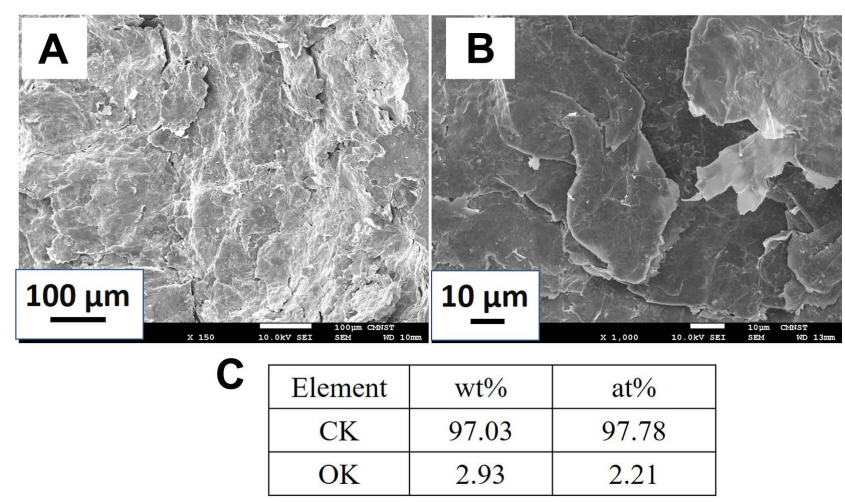

Fig. 2. FESEM micrographs showing (A) pristine few-layer graphene using magnifications: $\times 150(\mathrm{~A}), \times 1,000(\mathrm{~B})$, and elemental analysis using EDS with respective $w t \%$ and at $\%$ (C). FESEM, field emission scanning electron microscope; EDS, electron dispersive X-ray spectroscopy. CK and $\mathrm{OK}$ indicate carbon and oxygen measurements from $\mathrm{K}$ shell electrons, respectively. 

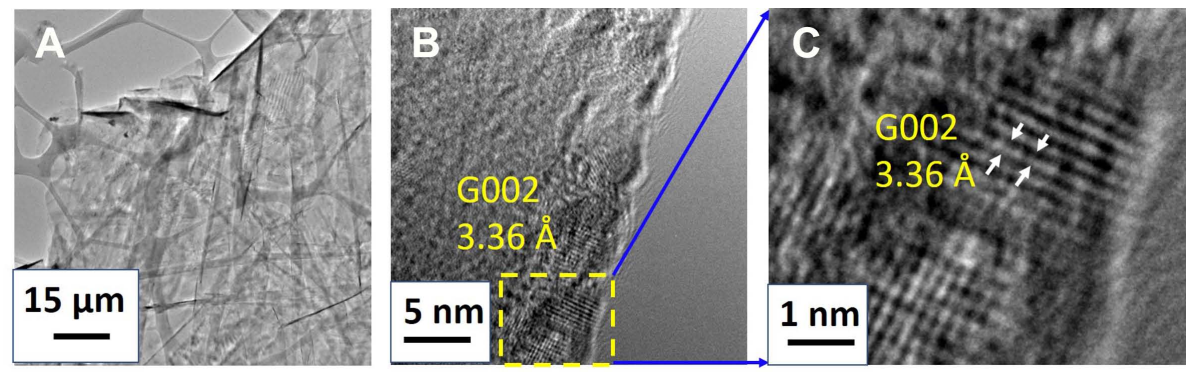

Fig. 3. HRTEM micrographs showing pristine few-layer graphene using magnifications: $\times 80,000(\mathrm{~A}), \times 400,000(\mathrm{~B})$, and $\times 600,000(\mathrm{C})$ with the graphite $\mathrm{G}$ (002) planes. HRTEM, high resolution transmission electron microscope.

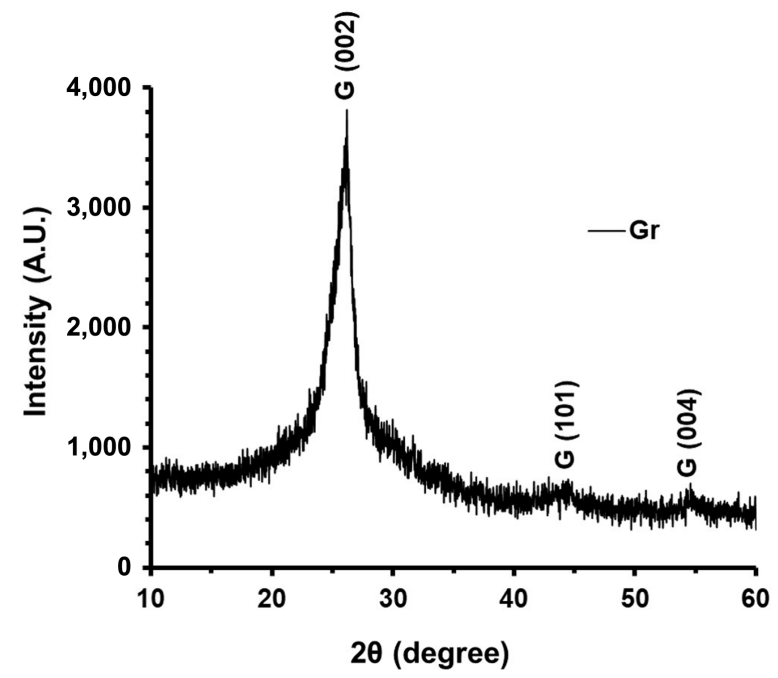

Fig. 4. X-ray diffraction of few layer graphene. G denotes graphite.

distance of $3.353 \AA$. This coupled with the EDS study in Fig. 2C shows the existence of graphitic structure between the graphene layers. The distance between graphene layers was measured at $>25$ different sites on graphene and found it consistent.

Crystallization study using XRD of pristine graphene is shown in Fig. 4. A major peak in the graph is visible at $2 \theta$ $=26.5$. This peak is the signature peak for (002) plains of graphite and denoted as G (002). The inter-planar distance for this peak was calculated as 3.36 which is consistent with the HRTEM and previous studies (Jaiswal et al., 2020; Malesevic et al., 2008; Mittal and Lin, 2020). It is also observed in the graph that this $\mathrm{G}(002)$ peak is wide at its base. This suggests the presence of small irregularity in the inter-planner distances in G (002) peak. Two very small peaks centred at $2 \theta=43.8,54.58$ have also appeared. These peaks correspond to the G (101) and G (004). Later peak is the second order of G (002) peak with an interplanar distance of 1.68 .

Electrochemical characterization and optimization of Ox-GNP modified ePAD. The electrochemical response

of the electrodes was characterized using CV and LSV. Initially, the current response for bare electrode and OxGNP modified ePAD were compared and it was seen that the current response of Ox-GNP modified ePAD increased substantially than the former (Figs. 1B and 5A). As seen in Fig. 5A the current response for the ssDNA/Ox-GNP ePAD decreased as compared to the Ox-GNP ePAD which is due to the non-conductive nature of biomolecule i.e., ssDNA, thereby decreasing the current response in comparison with the bare electrode (Fig. 1B).

For immobilization of ssDNA probe on to the circular working region of $\mathrm{ePAD}$ different concentrations (i.e., 20, $40,60,80$, and $100 \mu \mathrm{M})$ were taken. From the electrochemical analysis of Ox-GNPs with different probe ssDNA concentration (Figs. 1B, 5B, and 6B), a decrease in current response was observed with an increase in concentrations of ssDNA probe due to the deposition of a more insulating layer onto the working surface of the electrode. Based on these factors, $40 \mu \mathrm{M}$ was taken as the optimum concentration of ssDNA and further electrochemical analyses were done using this concentration. Similar results were reported earlier when graphene nano dots and zeolite modified ePAD was used for the detection of Staphylococcus aureus (Mathur et al., 2018). The current increased substantially with graphene nano dot and zeolite modified ePAD as compared to the bare electrode. The study also used 50 $\mu \mathrm{M}$ as the optimum concentration of ssDNA as at higher concentrations, the interaction of guanine bases of ssDNA with MB is inhibited (Mathur et al., 2018). In another study, $20 \mu \mathrm{M}$ and $10 \mu \mathrm{M}$ ssDNA probe concentration for electrochemical analysis were used during the detection of sugarcane white leaf disease and cucumber mosaic virus, respectively (Wongkaew and Poosittisak, 2014; Zulkifli et al., 2016).

Further, the target DNA at different concentrations were added to the ePAD. The sensor calibration of peak current at different concentration of target DNA, was done. A good linear relationship was established between current, and the logarithm of target DNA concentration ranged from $10 \mu \mathrm{M}$ to $10 \mathrm{fM}$. The equation for both target DNA is $y=-6.89 \mathrm{x}+$ 

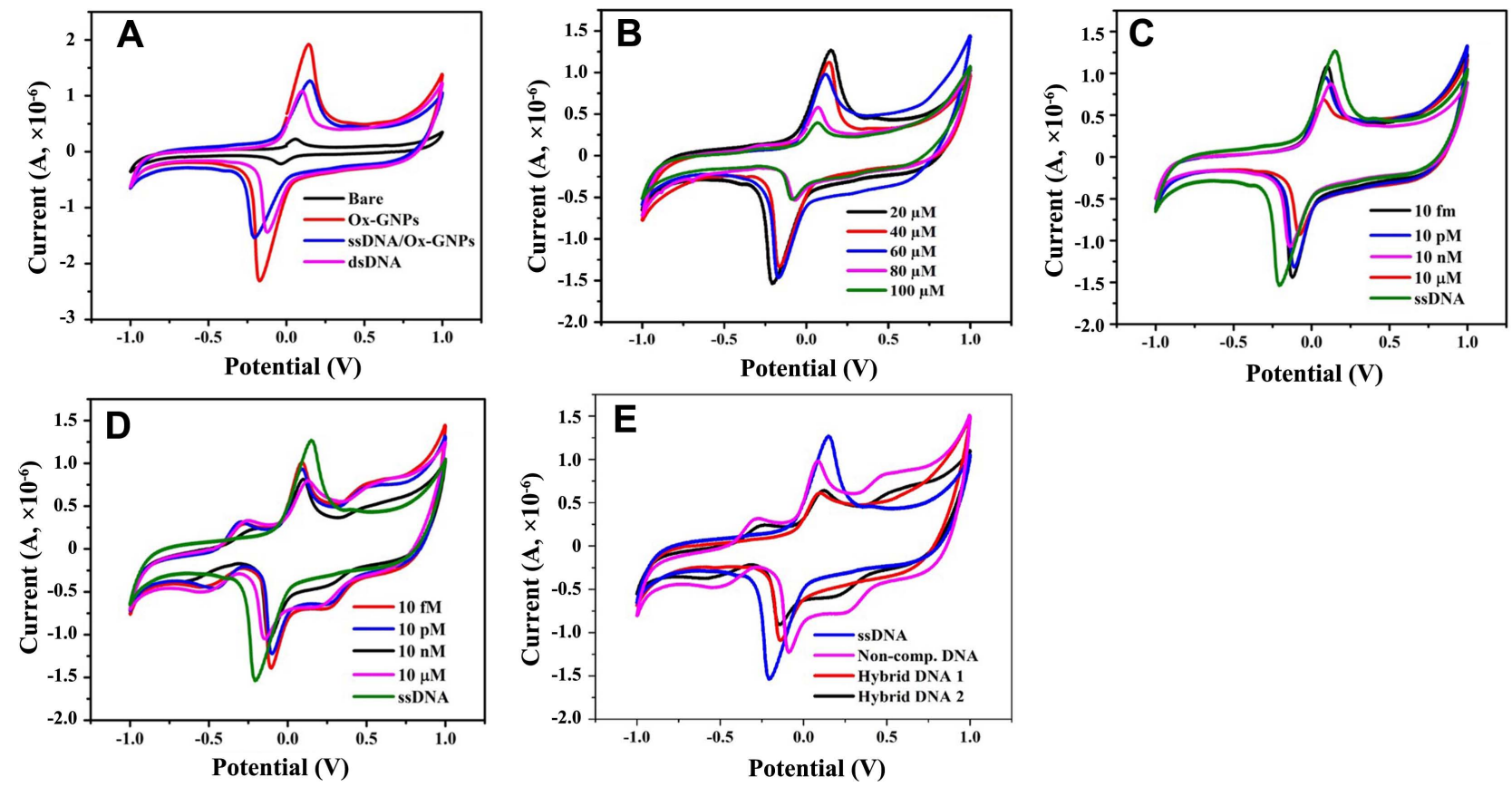

Fig. 5. Cyclic voltammograms of bare, Ox-GNPs and ssDNA/Ox-GNPs (A), Ox-GNPs with different probe ssDNA concentration (B), response of hybridization of Ustilaginoidea virens target DNA (T1) with ssDNA/Ox-GNPs ePAD (C), response of hybridization of $U$. virens target 2 DNA with ssDNA/Ox-GNPs/ePAD (D), and non-complementary DNA (E). All experiments were performed in the potential range -1.0 to $+1.0 \mathrm{~V}$. Ox-GNP, oxidised graphene nanoparticles; ssDNA, single-stranded DNA; ePAD, electrochemical paperbased analytical device.

$0.015\left(R^{2}=0.976\right)$ (Supplementary Fig. 1$)$. When the probe ssDNA was hybridized with the complementary target ssDNA, MB gets intercalated between G-C base pairs of the hybrid DNA. A decrease in current response from the ssDNA probe to dsDNA detection confirmed the hybridization of probe and target DNA (Wongkaew and Poosittisak, 2014). MB gets intercalated between the G-C base pairs, which thus results in a reduction in the current response (Mathur et al., 2018; Singhal et al., 2017). Also, as seen in Figs. $5 \mathrm{C}$ and $6 \mathrm{C}$, with an increase in target ssDNA, the current response further decreases due to intercalation of more quantity of MB with the G-C pair in dsDNA. These results are according to other studies reported (Kara et al., 2002; Mathur et al., 2018; Rohs and Sklenar, 2001). The results of this study indicated that the developed biosensor could detect $10 \mathrm{fM}$ of target ssDNA present in the buffer. The results indicated that it was an efficient sensor when compared to similar kind of devices (Mathur et al., 2018; Singhal et al., 2017; Wongkaew and Poosittisak, 2014), and had the potential for early detection of false smut pathogens in infected rice plant samples.

Selectivity of the sensor. To evaluate the selectivity of this platform, the device was tested using a non-complementary
ssDNA. CV analysis was done to study the selectivity of the device. As seen in Figs. 5E and 6E, the current response of the non-complementary DNA/ssDNA/Ox-GNPs/ePAD was more than target DNA/ssDNA/Ox-GNPs/ePAD, due to the incomplete hybridization and duplex formation of the non-complementary ssDNA with the probe ssDNA. This confirms the fact that the device is highly selective to the target DNA and can recognize it by a simplistic method without performing lengthy laboratory techniques.

Conclusion. In today's world, to prevent diseases from spreading to neighbouring plants, there is an ever-growing need for fast, reliable, and cost-effective point of care devices that are efficient and can detect the presence of pathogens even before the symptoms are visible. Hence, in our present work, we have demonstrated a paper-based sensor device for the detection of false smut of rice plant pathogen Ustilaginoidea virens. To improve the detection limit and efficiency of the device, oxidized graphene has been used. We were able to achieve a highly sensitive device with an enhanced limit of detection of $10 \mathrm{fM}$. The device fabricated in the study is also highly selective since the current response obtained by the CV and LSV analysis of the noncomplementary ssDNA with the ssDNA/Ox-GNP/ePAD 

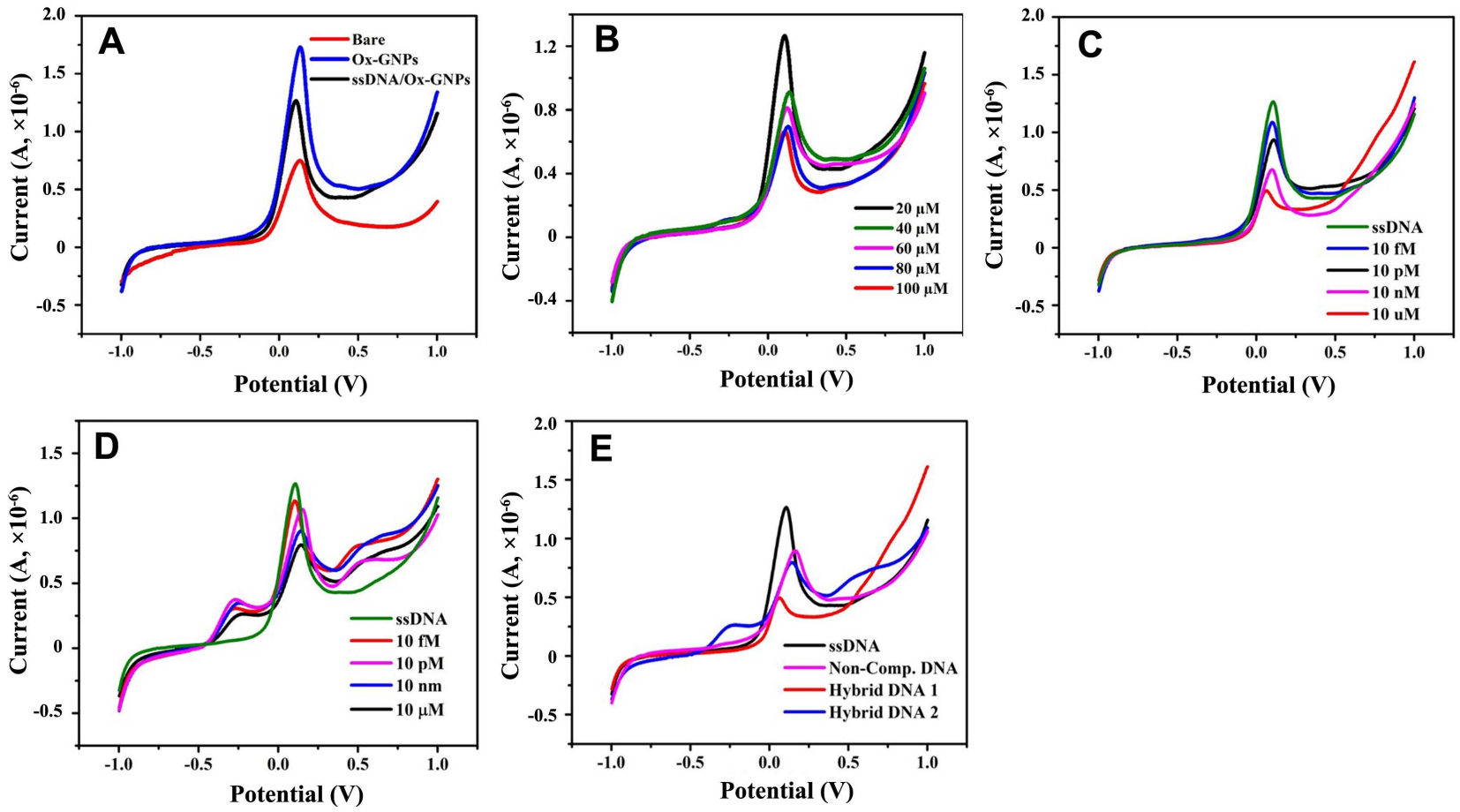

Fig. 6. Linear sweep voltammograms of bare electrode, Ox-GNPs/ePAD, and ssDNA/ox-GNPs/ePAD (A), Ox-GNPs/ePAD with different probe ssDNA concentration (B), response of hybridization of target ssDNA T1 with ssDNA/Ox-GNPs ePAD (C), response of hybridization of target ssDNA T2 with ssDNA/Ox-GNPs/ePAD (D), and non-complementary DNA (E). All experiments were performed in the potential range -1.0 to $+1.0 \mathrm{~V}$. Ox-GNP, oxidised graphene nanoparticles; ePAD, electrochemical paper-based analytical device; ssDNA, single-stranded DNA.

was more than that obtained from the hybridized DNA. This work could form the basis of further work, where the experiment for testing on real samples and on-field tests would be performed. Also, the device has the protentional to be tailored for different plant pathogens.

\section{Conflicts of Interest}

No potential conflict of interest relevant to this article was reported.

\section{Electronic Supplementary Material}

Supplementary materials are available at The Plant Pathology Journal website (http://www.ppjonline.org/).

\section{References}

Bhargava, P., Kumar, A. and Kumar, S. 2018. Epidemiological studies of false smut disease of rice (Ustilaginoidea virens) in Bihar. J. Pharmacogn. Phytochem. 7:1537-1540.

Cesewski, E. and Johnson, B. N. 2020. Electrochemical biosensors for pathogen detection. Biosens. Bioelectron. 159:112214.
Chen, Y., Qian, C., Liu, C., Shen, H., Wang, Z., Ping, J., Wu, J. and Chen, H. 2020. Nucleic acid amplification free biosensors for pathogen detection. Biosens. Bioelectron. 153:112049.

Chen, Y., Yao, J., Li, Y.-F., Wang, W.-X., Yang, X. and Zhang, A.-F. 2014. Simple and rapid detection of rice false smut pathogen Ustilaginoidea virens in rice seeds. Phytoparasitica 42:371375.

Cinti, S., Minotti, C., Moscone, D., Palleschi, G. and Arduini, F. 2017. Fully integrated ready-to-use paper-based electrochemical biosensor to detect nerve agents. Biosens. Bioelectron. 93:46-51.

Fang, Y. and Ramasamy, R. P. 2015. Current and prospective methods for plant disease detection. Biosensors 5:537-561.

Fu, X., Wang, A., Wang, X., Lin, F., He, L., Lai, D., Liu, Y., Li, Q. X., Zhou, L. and Wang, B. 2015. Development of a monoclonal antibody-based icELISA for the detection of ustiloxin B in rice false smut balls and rice grains. Toxins 7:3481-3496.

Jain, U., Pudake, R. N., Chauhan, N. and Pareek, S. 2021. Advancements in biosensors for fungal pathogen detection in plants. In: Biosensors in agriculture: recent trends and future perspectives: concepts and strategies in plant sciences, eds. by R. N. Pudake, U. Jain and C. Kole, pp. 205-216. Springer, Cham, Switzerland.

Jaiswal, M., Kumar, R., Mittal, J. and Jha, P. 2020. Synthesis of $\mathrm{CrO}_{3}$ intercalated multilayer graphene for rapid and reversible $\mathrm{NH}_{3}$ gas sensing. Sens. Actuators B Chem. 310:127826. 
Jiehua, Q., Shuai, M., Yizhen, D., Shiwen, H. and Yanjun, K. 2019. Ustilaginoidea virens: a fungus infects rice flower and threats world rice production. Rice Sci. 26:199-206.

Justino, C. I. L., Gomes, A. R., Freitas, A. C., Duarte, A. C. and Rocha-Santos, T. A. P. 2017. Graphene based sensors and biosensors. TrAC Trend. Anal. Chem. 91:53-66.

Kara, P., Kerman, K., Ozkan, D., Meric, B., Erdem, A., Ozkan, Z. and Ozsoz, M. 2002. Electrochemical genosensor for the detection of interaction between methylene blue and DNA. Electrochem. Commun. 4:705-709.

Khan, M. Z. H., Hasan, M. R., Hossain, S. I., Ahommed, M. S. and Daizy, M. 2020. Ultrasensitive detection of pathogenic viruses with electrochemical biosensor: state of the art. Biosens. Bioelectron. 166:112431.

Khatkar, B. S., Chaudhary, N. and Dangi, P. 2016. Production and Consumption of Grains: India. In: Encyclopedia of Food Grains, 2nd ed., eds. by C. Wrigley, H. Corke, K. Seetharaman and J. Faubion, pp. 367-373. Academic Press, Oxford, UK.

Khater, M., de la Escosura-Muñiz, A. and Merkoçi, A. 2017. Biosensors for plant pathogen detection. Biosens. Bioelectron. 93:72-86.

Krishnan, S. K., Singh, E., Singh, P., Meyyappan, M. and Nalwa, H. S. 2019. A review on graphene-based nanocomposites for electrochemical and fluorescent biosensors. RSC Adv. 9:87788881.

Kumar, V. and Arora, K. 2020. Trends in nano-inspired biosensors for plants. Mater. Sci. Energy Technol. 3:255-273.

Li, H., Ni, D., Duan, Y. B., Chen, Y., Li, J., Song, F. S., Li, L., Wei, P. C. and Yang, J. B. 2013. Quantitative detection of the rice false smut pathogen Ustilaginoidea virens by real-time PCR. Genet. Mol. Res. 12:6433-6441.

Li, Z., Yu, T., Paul, R., Fan, J., Yang, Y. and Wei, Q. 2020. Agricultural nanodiagnostics for plant diseases: recent advances and challenges. Nanoscale Adv. 2:3083-3094.

Lu, D.-H., Yang, X.-Q., Mao, J.-H., Ye, H.-L., Wang, P., Chen, Y.-P., He, Z.-Q. and Chen, F. 2009. Characterising the pathogenicity diversity of ustiiaginoidea virens in hybrid rice in China. J. Plant Pathol. 91:443-451.

Malesevic, A., Vitchev, R., Schouteden, K., Volodin, A., Zhang, L., Van Tendeloo, G., Vanhulsel, A. and Van Haesendonck, C. 2008. Synthesis of few-layer graphene via microwave plasma-enhanced chemical vapour deposition. Nanotechnology 19:305604.

Mathur, A., Gupta, R., Kondal, S., Wadhwa, S., Pudake, R. N., Shivani, Kansal, R., Pundir, C. S. and Narang, J. 2018. A new tactics for the detection of $S$. aureus via paper based genointerface incorporated with graphene nano dots and zeolites. Int. J. Biol. Macromol. 112:364-370.

Mittal, J. and Lin, K. L. 2020. Sn/SnO hybrid graphene for thermal interface material and interconnections with Sn hybrid carbon nanotubes. Mater. Sci. Eng. B 253:114485.

Morales-Narváez, E. and Merkoçi, A. 2019. Graphene oxide as an optical biosensing platform: a progress report. Adv. Mater. 31:1805043.

Narang, J., Malhotra, N., Singhal, C., Mathur, A., Chakraborty, D.,
Anil, A., Ingle, A. and Pundir, C. S. 2017. Point of care with micro fluidic paper based device integrated with nano zeolite-graphene oxide nanoflakes for electrochemical sensing of ketamine. Biosens. Bioelectron. 88:249-257.

Pannu, P. P. S., Thind, T. S. and Sanjay, G. 2010. Standardization of technique for artificial creation of false smut of rice and its management. Indian Phytopathol. 63:234-235.

Pudake, R. N., Chauhan, N. and Kole, C. 2019. Nanoscience for sustainable agriculture. Springer International Publishing, Cham, Switzerland. 711 pp.

Pumera, M. 2011. Graphene in biosensing. Mater. Today 14:308315.

Rohs, R. and Sklenar, H. 2001. Methylene blue binding to DNA with alternating GC base sequence: continuum treatment of salt effects. Indian J. Biochem. Biophys. 38:1-6.

Singh, R. A. and Dube, K. S. 1978. Assessment of loss in seven rice cultivars due to false smut. Indian Phytopathol. 31:186188.

Singhal, C., Pundir, C. S. and Narang, J. 2017. A genosensor for detection of consensus DNA sequence of Dengue virus using ZnO/Pt-Pd nanocomposites. Biosens. Bioelectron. 97:75-82.

Sun, W., Fan, J., Fang, A., Li, Y., Tariqjaveed, M., Li, D., Hu, D. and Wang, W.-M. 2020. Ustilaginoidea virens: insights into an emerging rice pathogen. Annu. Rev. Phytopathol. 58:363385.

Suvarnaphaet, P. and Pechprasarn, S. 2017. Graphene-based materials for biosensors: a review. Sensors 17:2161.

Tanaka, E. and Tanaka, C. 2008. Phylogenetic study of clavicipitaceous fungi using acetaldehyde dehydrogenase gene sequences. Mycoscience 49:115-125.

Tang, J., Zheng, L., Jia, Q., Liu, H., Hsiang, T. and Huang, J. 2017. PCR markers derived from comparative genomics for detection and identification of the rice pathogen Ustilaginoidea virens in plant tissues. Plant Dis. 101:1515-1521.

Wang, X., Fu, X., Lin, F., Sun, W., Meng, J., Wang, A., Lai, D., Zhou, L. and Liu, Y. 2016. The contents of ustiloxins A and $\mathrm{B}$ along with their distribution in rice false smut balls. Toxins $8: 262$.

Wongkaew, P. and Poosittisak, S. 2014. Diagnosis of sugarcane white leaf disease using the highly sensitive DNA based voltammetric electrochemical determination. Am. J. Plant Sci. 5:2256-2268.

Yang, X., Al-Attala, M. N., Zhang, Y., Zhang, A.-F., Zang, H.Y., Gu, C.-Y., Gao, T.-C., Chen, Y., Al-Attala, M. N., Ali, F., Li, Y.-F. and Ali, F. 2018. Rapid detection of Ustilaginoidea virens from rice using loop-mediated isothermal amplification assay. Plant Dis. 102:1741-1747.

Zhou, Y.-L., Izumitsu, K., Sonoda, R., Nakazaki, T., Tanaka, E., Tsuda, M. and Tanaka, C. 2003. PCR-based specific detection of Ustilaginoidea virens and Ephelis japonica. J. Phytopathol. 151:513-518.

Zulkifli, H., Salam, F., Saad, S. M., Abd Rahman, R., Rani, R. M., Karim, M. S. A. and Ishak, Z. 2016. Preliminary study of electrochemical DNA sensor for cucumber mosaic virus. Procedia Chem. 20:98-101. 